Peer review: This article has been subject to a double blind peer review process

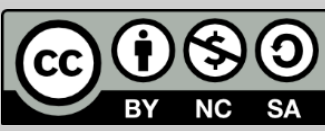

(C) Copyright: The Authors. This article is issued under the terms of the Creative Commons Attribution NonCommercial Share Alike License, which permits use and redistribution of the work provided that the original author and source are credited, the work is not used for commercial purposes and that any derivative works are made available under the same license terms.

\section{A Pedagogy of Movement: Interdisciplinary Approaches to Human Motion}

\section{Nefeli Chatzistefani* and Jonathan Heron}

Institute of Advanced Study and Institute for Advanced Teaching and Learning, University of Warwick

*Correspondence: N.Chatzistefani@warwick.ac.uk

\begin{abstract}
This critical reflection documents a collaboration between an arts practitioner-researcher and a biomedical engineer in the field of interdisciplinary pedagogy. From one perspective, we read movement as a cultural practice engaging theories of embodiment and informed by dance studies; from another perspective, we study movement as a product of internal and external forces acting on the body and we investigate the science behind the structure and function of human motion. This article reflects upon these differences and considers opportunities for new experimentation within interdisciplinary movement studies, in particular, the co-authors reflect upon the various definitions and affordances of the term 'bio-mechanical' and its application to movement and motion capture. The article ends with an overview of the experiments yet to be undertaken within transdisciplinary pedagogy at the Institute for Advanced Teaching and Learning (IATL), University of Warwick.
\end{abstract}

Keywords: movement; pedagogy; interdisciplinary; bio-mechanical; motion-capture

\section{Introduction}

This article takes the form of a critical reflection between an arts practitioner-researcher and a bio-medical engineer in the field of interdisciplinary pedagogy. We begin with an account of the scientific methodology, before proceeding to develop these ideas with perspectives from the arts and humanities. Our dialogue then continues with further reflections on the application of biomechanical research to cultural practices, such as dance and sport. This example gives way to a wider consideration of motion capture in relation to somatic practices and movement studies. The article concludes by identifying experiments within this interdisciplinary collaboration, yet to be undertaken. 


\section{A Scientific Perspective}

Biomedical engineering is a discipline that delivers state-of-the-art knowledge in engineering, biology and medicine. Its main aim is to apply basic engineering principles and design concepts to medicine and biology in order to improve human healthcare. This field seeks to improve and develop health care treatment, including diagnosis, monitoring, and therapy through cross-disciplinary activities. Areas of interest within biomedical engineering include the study of motion, the deformation of materials, the movement within the body and in devices, and the transport of chemical components across biological and synthetic media and membranes. Engineers use biomechanics to solve biological or medical problems. Biomechanics is the science that studies the internal and external forces that act on the human body and the effects produced by these forces. Knowledge of the anatomy and physiology of the human body is thus a crucial aspect of biomechanics, since it helps in understanding the mechanisms responsible for human movement.

Movement can be defined as the action or process of moving, i.e. the change of position, place or posture. Movement of the musculoskeletal system is usually controlled consciously by humans. However, there is movement in human bodies such as breathing, heart beating, bloodstream etc. that is performed unconsciously (D'Ostilio and Garraux, 2012). In this critical reflection, we are dealing with the consciously controlled movement in humans. When a person decides to move a specific part of their body (such as a hand, a leg or a toe), the part of the brain called the motor cortex sends an electrical signal to the spinal cord which then sends out signal pulses to the local nerves. These signals reach the muscles and they result in muscle contraction and initiation of movement. While the movement is performed, a wide variety of receptors in our skin, muscles, and bones provide feedback regarding the speed, direction, and force of the movement. This feedback gets transmitted via nerves and the spinal cord back to the brain, allowing it to co-ordinate, adjust and fine-tune the movement and the body's position accordingly (Wonderopolis, 2014-2017).

\section{An Artistic Perspective}

Drawing upon theatre practice and performance scholarship to consider biomechanics and movement takes us into a radically interdisciplinary mode. From a modernist perspective 'biomechanics' was a tradition of aesthetic movement and performer training 'associated with the acting theories of Vsevolod Meyerhold... based on external mastery of physical movement, rather than on inner emotional states of empathetic feeling' 
(Kennedy, 2010). This tradition is therefore focused upon the actor's physicality and shares elements with acrobatics, gymnastics and nonWestern movement forms. Within biomechanics, as a performance practice, collaborative effort and ensemble playing would be encouraged over individualised characters or leading actors. Its legacy can be seen in 'physical theatre' and narrative forms of contemporary dance.

More broadly, the organism of the performer has been placed in opposition to the mechanism of the production across dance, theatre and film. As extensively documented by Joseph Roach in The Player's Passion: Studies in the Science of Acting (1993), the modernist body in nineteenth-century performance was imagined as a 'reflex machine' that stages a problem between 'machinery and organisms' (Roach, 1993). Furthermore, early-twentieth century neurologists imagined the brain as a machine constructing organic consciousness, with Santiago Ramon y Cajal being the first to describe the nervous system as 'organic machinery' in 1904 (Salisbury and Shail, 2010). A central concern for theatre studies is how this experimental legacy informs contemporary performance practice (Heron, 2015).

The 'biomechanical' element therefore allows arts practitioners to rethink the human body as experimental apparatus, a sculptural instrument, an aesthetic machine, and in doing so, recall a philosophical history of embodiment that places sensory movement at the heart of meaning-making. Within a tradition of dance scholarship, the shift from 'the documentation of a phenomenon, to problematizing the production of knowledge' (O'Shea and Carter, 2010) has characterised the institution of dance and movement as a discipline in its own right. Within dance studies, as imagined at the turn of the millennium, there were at least four ways of 'reading' human movement: 'anthropology, folklore and ethnography; the writings of expert viewers and dance analysis; philosophy, especially aesthetics and phenomenology; historical studies including biography and dance reconstruction' (2010: 2). While twentyfirst century dance and movement studies may have developed new concerns and more nuanced methods, the core practice of studying human movement has been sustained and transformed by digital technologies and collaborative research with the sciences.

\section{Biomechanical Engineering and Motion Capture}

Biomechanics in sports and dance can be described as the study of muscular, joint and skeletal activity the body performs when given a task or asked to execute a specific movement (Yessis, 2008). Generally, in order to help an athlete or dancer gain a greater understanding of their 
performance, enhance their skills, prevent injuries from happening and assist in rehabilitation, the laws of mechanics applied to human movement are studied (Bartlett, 1997). Methods and elements from different disciplines of engineering are used in sports biomechanics in order to define, examine and analyse movement. Examples of these include force sensors from mechanical engineering, force plates from gait analysis, surface electromyography (EMG) from clinical neurophysiology, digital filtering from electrical engineering and numerical methods from computer sciences.'

When describing movement from a biomedical engineering perspective, it is essential to understand how the human body works by investigating its anatomy. The skeletal system of the human body consists of the bones and their cartilages, together with tendons and ligaments. The skeleton supports the soft tissues, provides attachment points for the tendons of most skeletal muscles and therefore serves as a structural framework to the human body (Tortora, 2011). Even though bones form the framework of the body and provide stabilisation, they cannot move body parts by themselves. Motion and movement come from the alternation of contraction and relaxation of muscles. Most skeletal muscles attach to the bones by tough, fibrous tissues called tendons and they produce movement when contracting by pulling the bones down (Marieb, 2007). When a muscle contracts, a force is generated; this force then passes through the muscle and its associated tendon and vice versa depending on the movement. This force is responsible for initiating movement in the connected bone and associated joint that are attached to the tendon. Tendons, muscles, joints and bones form the musculoskeletal system of a human body.

Over the years the need for new information on the characteristics of normal and pathological human movement has inspired the evolution of methods for the capture of human movement. The most advanced and frequently used method is 3D motion capture. Marker based motion capture systems use infra-red cameras to track distinctive reflective markers attached to anatomical or geometrical locations of subjects or objects. This allows joint motion in the foot or other parts of the body, to be measured quantitatively during normal function. Also, the position of specific parts of the body can be calculated in 3D space and time. A force plate is used to record the total force exerted on the plate during a dynamic experiment. This helps in identifying the forces transmitted from muscles to tendons and vice versa. In addition to the infrared cameras, several laboratories use digital video (DV) cameras that allow the capture of movement in real time in a synchronised way with the infrared cameras, in order to provide a clearer image of the original motion. 
Motion capture and videography have been used broadly in modern medicine not only to observe gait analysis, but also to assist in different disciplines. For example, they have been employed in rehabilitation clinics to assist in developing and monitoring rehabilitation programs for patients that have suffered strokes or that have had accidents or suffer from other pathologies affecting their gait and for children with genetic muscular abnormalities. Another field that has used motion capture systems and videography is orthotics and prosthetics where the technology has been used to improve orthotic design prescriptions and to assess the progress of a patient using orthotics during a therapy program. Motion capture systems are also widely used with the assistance of pressure monitors, such as insole pressure sensors, in order to examine and evaluate specific abnormalities and pathologies of the foot such as foot drop (Switaj and O'Connor, 2008). Furthermore, motion capture systems are used in films and motion capture movies to create animated figures from the actual movements and facial expressions of the actors. Last but not least, medal-winning Olympic athletes have performed their sports while using these motion capture systems in order to fully understand which muscles they use, what forces act on their bodies when they perform their sport and to investigate the interaction between any one body part and the body as a whole.

\section{Performance and Motion Capture}

If capture is to take, to seize or to grasp, then what is at stake when we record movement in this way? One concern here would be the translation of movement from the body to the machine, in ways yet to be fully theorised. When we watch the characters Golem (The Lord of the Rings) or Caesar (The Planet of the Apes) are we still watching Andy Serkis - the original actor who performed those movements - or are we now watching a hybrid subject on screen, which is neither human nor animation, somehow non-human? It could be argued that the repertoire of embodied human movement is still there in the moving image, in a way comparable to a dancer learning another dancer's moves. Indeed, there is a tradition of scholarly dance analysis, and especially notation, to which we can now turn, to improve our movement literacies on screen.

This allows us to recall the tradition of dance analysis, specifically the influence of Rudolf Laban's work upon the practice of choreographers and theatre artists. Laban Movement Analysis (LMA), and its 'system of analysing and recording movement' through 'Labanotation' (HutchinsonGuest, 2005), was developed in order to document and replicate complex dance forms. It has subsequently been used in a diverse range of disciplines and within various body-based contexts: sport, therapy and 
medicine. These practitioners have begun to develop a model of Laban's 'effort attitudes' for use by workshop participants within arts education and participatory projects. Their activities are designed to be accessible to all and begin with establishing contact with the floor through posture, alignment and breathing exercises."

In short, future collaborations should unify work on the science and art of motion, leading to the creation of new laboratories for the 'capture' of creative and complex movement. This work will therefore build upon a modernist legacy of technical innovation in tandem with shifting philosophies of human embodiment (e.g. phenomenology), in order to articulate an interdisciplinary practice for the study of contemporary movement. In preparation for this work, we have identified some questions about methodologies and pedagogies for interdisciplinary movement research:

1) How can the study of movement be enhanced through the collaborative perspective of an arts practitioner-researcher and a biomedical engineer?

2) How can this collaboration contribute to interdisciplinary movement pedagogies and transdisciplinary pedagogy more broadly?

3) In what ways, and according to which principles, can we plan, design and conduct experiments within transdisciplinary pedagogy?

\section{Conclusions and Future Work}

This critical reflection has shown that human motion is of mutual interest to both the arts and the sciences, with reference to performance studies, biomechanical engineering and transdisciplinary pedagogy. We will be working with the transdisciplinary pedagogy of Open-space Learning in which, 'normally stable discipline boundaries are suspended in the interaction of participants' subject knowledge [and where] trans-space exists by virtue of a dialectical process between various thesis and antithesis that in the moment of their opposition create an "open" space in which new syntheses develop' (Monk et al., 2011). We therefore predict that our 'open-space' experiments on human motion will develop a new case-study within transdisciplinary pedagogy, especially when integrating research perspectives into a new pedagogy of movement. Locating these experiments within a cross-faculty environment will enable this investigation to transcend methodological boundaries and, over time, achieve better pedagogic outcomes for Warwick students. In order to address the questions raised above, we will adapt models of practice developed through the IATL Student Ensemble and within the department's interdisciplinary modules.iii 


\footnotetext{
' Usually, force sensors are transducers that convert an input of a mechanical force into an electrical output signal. Force plates are measuring instruments that measure the ground reaction forces generated by a body standing or moving across them. Surface electromyography is a technique where electrodes are placed on the skin overlying a muscle in order to identify the electrical activity of the muscle in question. Digital filtering is a mathematical operation used on a discrete-time signal in order to reduce or enhance certain aspects of that signal. Numerical methods are mathematical tools like 'algorithms' designed to solve numerical problems. Force sensors, force plates and surface EMGs are used during biomechanical experiments, while digital filtering and numerical methods are used when analysing the experiments.

ii For example, during a recent workshop at the University of the Pacific (Stockton, California, USA), Lisa Tromovitch hosted an event that sought to develop Laban's method within the contemporary framework of movement skills for motion capture. In collaboration with Gina Bloom (UC Davis, USA), Katie Brokaw (UC Merced, USA) and Jonathan Heron \& Paul Prescott (Warwick, UK), educators developed new ways to explore Shakespeare's The Tempest through practical movement exercises and digital technologies of motion capture. One important finding on that day (27 April 2017) was that Laban's 'efforts' had a new application within the world of motion capture, especially as they represent an open system and a movement vocabulary for all kinds of human play, even when mediated.

iii For examples of institutional practice informed by Open-Space Learning, please visit IATL's webpages at: https://www2.warwick.ac.uk/fac/cross fac/iatl/.
}

\section{References}

Bartlett, R. (1997), Introduction to sports biomechanics, New York: Routledge

D'Ostilio, K. and G. Garraux (2012), 'Brain mechanisms underlying automatic and unconscious control of motor action', Frontiers in Human Neuroscience, 6, 265

Heron, J. (2015), 'A different kind of failure: towards a model of experimental theatre as transdisciplinary performance', PhD thesis, University of Warwick

Hutchinson-Guest, A. (2005), Labanotation: The System of Analyzing and Recording Movement, New York: Routledge

Kennedy, D. (2010), The Oxford Companion to Theatre and Performance, Oxford: Oxford University Press

Marieb, E.N., and K.N. Hoehn (2007), Human Anatomy \& Physiology, San Fransisco: Pearson Benjamin Cummings 
Monk, N., C. Chillington-Rutter, J. Neelands and J. Heron (2011), Openspace Learning: A Study in Transdisciplinary Pedagogy, London: Bloomsbury Academic

O'Shea, J. and A. Carter (2010), The Routledge Dance Studies Reader 2nd Edition, London: Routledge.

Roach, J. (1993), The Player's Passion: Studies in the Science of Acting, Ann Arbour: University of Michigan Press

Salisbury, L. and A. Shail (2010) Neurology and Modernity: A Cultural History of Nervous Systems, 1800-1950, Basingstoke: Palgrave Macmillan

Switaj, T. L. and F.G. O'Connor (2008), 'Chapter 43 - Gait Analysis', in Seidenberg, P. (ed.), The Sports Medicine Resource Manual, Philadelphia: W.B. Saunders

Tortora, G. J. and B. Derrickson (2011), Principles of Anatomy \& Physiology, Oxford: John Wiley and Sons

Wonderopolis (2014-2017), National Center for Families Learning, http://wonderopolis.org/wonder/how-do-we-move, accessed 10 July 2017.

Ywssis, M. (2008), Secrets of Russian Sports Fitness and Training, Ultimate Athlete Concepts

\section{To cite this article:}

Chatzistefani, N. and Heron, J. (2017). A Pedagogy of Movement: Interdisciplinary Approaches to Human Motion. Exchanges: the Warwick Research Journal, 5(1), 98-105. Retrieved from:

http://exchanges.warwick.ac.uk/index.php/exchanges/article/view/213 